\title{
O ALFABETO HEBRAICO: ORIGEM DIVINA VERSUS HUMANA
}

\author{
Manu Marcus Hubner*
}

\section{Resumo}

A escrita é um fantástico sistema de comunicação humana, uma das maiores realizações da humanidade. Sua necessidade para o conhecimento humano resulta do fato de que a tradição oral pode ter valor inestimável, mas talvez não seja suficiente para proporcionar ao conhecimento humano um caráter permanente ou para registrar uma história com perfeição. A escrita evoluiu dos métodos de comunicação antigos, passando por diversos estágios de desenvolvimento, provavelmente lentos, até chegar aos dias de hoje como uma coleção de um pequeno número de símbolos, conhecidos como letras, que representam sons da fala humana. A tradição da invenção da escrita perdeu-se nos tempos antigos, quando muitos povos acreditavam na origem divina da escrita. A história da invenção do alfabeto hebraico confunde-se com a história da invenção do próprio alfabeto. $\mathrm{O}$ alfabeto hebraico mantém, até os dias de hoje, o mesmo número de letras, na mesma ordem, e com os mesmos valores fonéticos que possuíam os alfabetos semíticos primitivos há mais de três mil anos, enquanto diversos outros alfabetos sofreram alterações. O objetivo deste trabalho é discutir a origem do incrível alfabeto hebraico.

Palavras-chave: Hebraico, Alfabeto, Alef, Torá, Letras

\footnotetext{
* Doutorando pelo Programa de Pós-Graduação em Estudos Judaicos e Árabes do Departamento de Letras Orientais da Faculdade de Filosofia, Letras e Ciências Humanas, da Universidade de São Paulo.<marcush@usp.br>
} 


\section{Abstract}

Writing is a fantastic system of human communication, one of the greatest achievements of mankind. The need of writing for human knowledge results from the fact that the oral tradition can be invaluable, but perhaps not enough to provide a permanent human knowledge or to register a story to perfection. Writing evolved slowly from ancient methods of communication, through a few stages of development, until present days as a collection of a small number of symbols, known as letters, representing sounds of human speech. The information on who created writing was lost in ancient times, when many people believed in the divine origin of writing. The history of the invention of the Hebrew alphabet is intertwined with the history of the invention of the alphabet itself. The Hebrew alphabet has, until the present day, the same number of letters in the same order, and with the same phonetic values that the primitive Semitic alphabets had for over three thousand years, while several other alphabets have changed. The objective of this paper is to discuss the origins of the amazing Hebrew alphabet.

Keywords: Hebrew, Alphabet, Aleph, Torah, Characters

\section{Origem divina}

$\mathbf{N}^{2}$

Tradição Judaica ${ }^{1}$, existem alusões à origem divina do alfabeto hebraico. Porém, no texto literal da Bíblia Hebraica, não há descrições claras de como teria sido esta invenção ou mesmo um possível processo de evolução deste alfabeto.

No livro Yetsirá 2:2² há o seguinte relato: "Vinte e duas letras: Deus as gravou, esculpiu, permutou, pesou, transformou, e com elas Ele descreveu tudo o que formou e tudo o que seria formado" (KAPLAN, 2002, p. 126).

Para Ginzberg (2001, p. 195 e 228), a Torá foi criada dois mil anos antes do

1 O Judaísmo se baseia nos ensinamentos da Torá e do Talmude. A Torá, que quer dizer "ensinamento" (BEREZIN, 2003, p. 663) é o conjunto de livros que forma o Pentateuco. A Bíblia Hebraica, ou Tanach, é composta pelos livros do Pentateuco, Profetas e Escritos. Talmude quer dizer "instrução, estudo" (BEREZIN, p. 669), uma das obras fundamentais do Judaísmo, considerada sua "lei oral", que consta de discussões rabínicas sobre diversos temas, como leis, ética e filosofia. Possui dois componentes: a Mishná, compilada em 220 d.C., e a Guemará, por volta de 500 d.C.

2 Sefer Yetsirá é o Livro da Criação, livro antigo de Cabala escrito em Israel antes da era talmúdica, segundo Berezin (2003, p. 278). 
mundo, e escrita com o alfabeto hebraico, conforme consta na introdução do livro Zohar ${ }^{3}$, indicando que o alfabeto hebraico deve ter antecedido a criação da Torá. As 22 letras do alfabeto hebraico foram os instrumentos utilizados na criação do mundo, tendo ficado, durante o período de dois mil anos entre a criação da Torá e a criação do mundo, em estado de ocultação, simplesmente como objetos para o prazer e agrado divinos.

O Talmude (Sanhedrin 104a) afirma que a Torá foi dada por meio do alfabeto hebraico, confirmando que o alfabeto hebraico deve ter sido criado antes da própria Torá. O próprio Talmude ( $\mathrm{C}$ hagiga $12 \mathrm{a}$ ) menciona as dez criações do primeiro dia: o céu e a terra, o caos e a desolação, a luz e a escuridão, o vento e a água, e a duração do dia e da noite. Tudo o que foi criado bem no início do processo da criação do mundo já possuía um nome específico, sugerindo que já havia alguma linguagem antes mesmo da criação do mundo.

Mordell (1912, p. 581 e 583), citando o enigmático Livro de Raziel, traz uma teoria interessante sobre a origem das letras hebraicas: Adão gravou as letras hebraicas no formato da aparência de anjos que foram repreendidos e expulsos dos céus. Porém, as letras do tetragrama ${ }^{4}$ são imagens e figuras de anjos superiores. A narrativa sobre a origem das letras no livro Yetsirá conclui afirmando que Deus amarrou as 22 letras da Torá na língua de Abraão e lhe revelou os segredos destas letras. Curiosamente, Philo atribui a invenção das letras a Abraão.

Em Gênesis $11: 1^{5}$, no início da narrativa do episódio da Torre de Babel, a Bíblia Hebraica sugere a existência de uma única língua com a seguinte afirmação: “[...] toda a terra tinha uma língua e mesmas palavras", e no verso 6: "[...] uma mesma língua para todos eles". De acordo com Rashi ${ }^{6}$, quando Gênesis 11 se refere a uma única língua, significa o "hebraico". O desfecho desta narrativa é a modificação desta situação de língua única, com a dispersão dos povos e a formação de diversas linguagens, como consta do verso 9: "[...] ali

3 A palavra Zôhar significa "brilho, luz, esplendor"; o livro do Zôhar, que é parte da Cabala, foi escrito provavelmente no séc. XIII por Rabi Mosché de Leon, e há a crença de que foi composto pelo círculo de Rabi Schimon Bar Yokhai, no séc. II. (BEREZIN, 2003, p. 207).

4 Nome de Deus de quatro letras.

5 As abreviações dos livros da Bíblia seguem o padrão da Bíblia de Jerusalém.

6 Rashi: Rabi Shelomô Yitschaki (1040-1105) de Troyes, França. (The Pentateuch and Rashi’s Commentary: Genesis, 1976, comentário sobre Gn 11:1). 
confundiu o Eterno a língua de toda a terra”. Segundo Ginzberg (2001, p. 195), Deus designou para cada um dos 70 anjos que cercavam seu trono um povo e uma língua, assim, uma língua foi designada para cada povo. Esta é a origem bíblica das línguas, com exceção do hebraico, que já havia sido criado.

Há também versos da Bíblia Hebraica relacionados à escrita, como, por exemplo: "Escreve isto para lembrança no livro [...]" (Ex 17:14), "Escreve para ti estas palavras [...]" (Ex 34:27), “[...] e as pedras serão segundo os nomes dos filhos de Israel, doze, segundo seus nomes, como gravuras de selo cada um [...]" (Ex 28:21), “[...] e gravarás sobre ela, como gravuras de selo, 'Santidade ao Eterno"” (Ex 28:36).

Chomsky (1958, p. 18) acredita que, segundo a Bíblia, todas as línguas derivariam do hebraico, por duas razões: primeira, o hebraico é a língua usada nas conversas entre Deus e Adão e Eva (Gn 3); segunda, as palavras homem e mulher derivam da mesma raiz no hebraico: "[...] a mulher foi chamada ishah porque foi tirada do homem" (Gn 2:23).

Segundo Benner (2004, p. 4-7), de Gênesis 11:1 podemos concluir que Deus, Adão, Eva e seus descendentes falavam hebraico. Em Gênesis 1:3, Deus dá nomes hebraicos a toda a criação, desde a luz, o céu e a terra, até os astros e o homem. $\mathrm{O}$ homem usou a mesma língua para nomear os animais. A primeira indicação bíblica de escrita está em Gênesis 4:15, quando Deus põe uma "marca" (em hebraico, ot) em Caim. A palavra ot significa também "letra", ou seja, possivelmente a "marca" seria uma "letra". Em Gênesis 5, estão relacionados os descendentes de Adão, todos nomes com significado em hebraico. Por exemplo, Adão significa "homem", Noé significa "conforto", já que ele trouxe conforto para seu povo (Gn 5:29). Somente após o episódio da Torre de Babel, após a punição dos homens, é que encontramos três grandes línguas: egípcio, sumério e hebraico.

O Talmude (Sanhedrin 22a), afirma que a escrita e a linguagem dos judeus não sofreu alterações com o tempo, conforme atesta Diringer (1964, p. 11), que afirma que o alfabeto hebraico contém o mesmo número de letras, na mesma ordem, e com os mesmos valores fonéticos que o primitivo alfabeto semítico presente em inscrições do segundo milênio antes da era comum, assim como o alfabeto hebraico usado nos dias de David e Salomão. Curiosamente, a história do grego, latim, russo, árabe ou de outra escrita alfabética qualquer está 
cheia de alterações, como a adição ou a eliminação de símbolos, mudanças na pronúncia ou a combinação de dois ou mais símbolos para representar um único som.

Segundo o Talmude (Sanhedrin 21b), a Torá foi originariamente escrita em letras hebraicas e na língua hebraica. Bem mais tarde, na época de Ezdras (por volta de 516 A.E.C., ano da reconstrução do Templo de Jerusalém [BARNAVI, 1992, p. 29]), a Torá foi escrita em letras assírias (letras hebraicas quadradas modernas) e língua aramaica. Finalmente, a escolha de Israel foi a escrita assíria com a língua hebraica, abandonando as letras hebraicas e a língua aramaica em prol de um povo chamado de hedyototh, que o próprio Talmude identifica com os samaritanos, trazidos por Sargão, rei da Assíria, para tomarem o lugar dos israelitas exilados (2Rs 17:24-41). O Talmude afirma, ainda, que a razão para esta mudança das letras hebraicas para assírias foi criar uma barreira maior do que aquela que já existia entre samaritanos e judeus (Ez 4; Ne 2:19; 3:33-35; 4; 6). Letras hebraicas passaram a significar escrita libuna'ah, que pode significar caracteres grandes empregados em amuletos, o nome de algum lugar (talvez Líbano) ou uma variação da palavra lebenah, que significa "tijolo", e pode estar referindo-se à escrita em tábuas de argila.

Além da origem das línguas, no episódio da Torre de Babel, em Gênesis 11:1-9, é interessante notar que a Bíblia Hebraica registra outras origens, como, por exemplo, a origem da agricultura e da criação de ovelhas, em Gênesis 4:2, "E foi Abel pastor de ovelhas, e Caim foi lavrador da terra"; nomadismo e criação de gado, em Gênesis 4:20, "[...] ele foi mestre dos que habitam em tendas e possuem gado"; origem da música, em Gênesis 4:21, “[...] ele foi pai de todos os que tocam lira e harpa"; e da metalurgia, Gênesis 4:22, “[...] artesão de todo artefato de cobre e ferro".

Os povos antigos em geral acreditavam em uma origem divina da escrita: para os egípcios, o inventor da escrita foi Tot (deus inventor dos elementos culturais) ou Ísis; para os babilônios, Nebo, filho de Marduk (deus do destino humano), ou Namar-Bili; para os chineses, face de dragão Ts'ang Chien; para os gregos, Hermes ou Cadmos; para os romanos, Mercúrio; para os teutões, Odin ou Wotan; para os celtas, Ogmios; para os astecas, Quetzacoatl. Segundo Heródoto, Cadmos, príncipe fenício, filho de Agenor, rei de Tiro, foi quem trouxe o alfabeto fenício para os gregos (CHOMSKY, 1958, p. 80). 


\section{Origem humana da escrita e seu desenvolvimento}

Para Diringer (1964, p. 11), a história do alfabeto hebraico deve começar com a origem do alfabeto.

Chomsky (1958, p. 73-4) afirma que a motivação para o surgimento da linguagem foi o desejo de expressão e a necessidade de comunicação de desejos e ideias. A escrita surge da necessidade de comunicação entre pessoas cujas linguagens são incompreensíveis. A linguagem falada provavelmente já possuía um grande e variável vocabulário antes do homem conseguir se comunicar graficamente de maneira inteligível.

Para Burgierman (1999, p. 57), “[...] a escrita foi inventada para organizar uma sociedade que se tornou complexa". Os homens antigos perceberam que a nova ferramenta, além de facilitar as contas, era o melhor jeito de se dirigir aos deuses, guardar a história e fazer poesia.

Segundo Diringer (1964, p. 17-19), a escrita é o “[...] mais importante sistema de comunicação humana por meio de símbolos convencionais", um sistema que se desenvolveu de forma lenta e natural, e tornou-se uma das maiores realizações da cultura humana. A escrita confere permanência ao conhecimento humano. Sem letras, não pode haver conhecimento permanente. A tradição oral e a mitologia preservadas nas mentes humanas podem ser um oceano cheio de pérolas, mas não são suficientes para registrar uma história genuína, real e fidedigna.

Ifrah (1989, p. 209-210) afirma que a invenção do alfabeto foi decisiva na história da civilização, por ter oferecido a possibilidade de escrever todas as palavras de uma língua com um pequeno número de signos fonéticos simples, as letras.

Não sabemos quem foi o inventor da escrita, a tradição da invenção perdeuse nos tempos antigos (DIRINGER, 1964, p. 19), mas os primeiros passos na direção de uma escrita alfabética, ao que tudo indica, foram dados no segundo milênio A.E.C., segundo Healey (1996, p. 260-262). Há inscrições no Sinai e em Israel, denominadas protossinaíticas ou protocananeias.

Há uma série de inscrições breves, exemplo de alfabeto proto-sinaítico, de cerca de 1700 A.E.C., feitas por mineiros de Serabit el-Khadem, na Península do Sinai, descobertas por Sir Flinders Petrie em 1905 (Figuras 1 e 2). Existem exemplos similares em Shechem, Guezer e Laquis. Esta escrita possui influ- 
ência egípcia - há semelhanças com os sinais egípcios, mas trata-se de uma escrita em cananeu, língua semítica ocidental, levando à possível conclusão de que esta escrita surgiu numa região semítica onde havia laços com o Egito. Goldwasser (2010) defende que a invenção do alfabeto em Serabit el-Khadem foi feita pelos cananeus que não conheciam os hieróglifos egípcios. Diringer (1964, p. 35-36) afirma que essas inscrições representam um estágio da escrita intermediária entre os hieróglifos egípcios e o alfabeto semítico do norte. A Teoria Protossinaítica sobre a origem da escrita, de 1916, criada por Sir Alan Gardiner, baseia-se nestas inscrições. O sistema egípcio, essencialmente silábico e sem vogal definida, usava um sinal para representar a primeira letra de determinada palavra, princípio chamado de acrofonia ("som inicial"). Os autores das inscrições protossinaíticas/cananeias foram mais além: a criação de um alfabeto chamado linear, com um número de sinais muito pequeno (menos de trinta). A primeira letra da palavra (semítica, não egípcia) é o sinal para nomear o objeto do pictograma original. Em semítico ocidental, "casa" era bet, então o pictograma "casa" foi usado para indicar a consoante bet. Este princípio acrofônico pode não explicar todos os sinais.

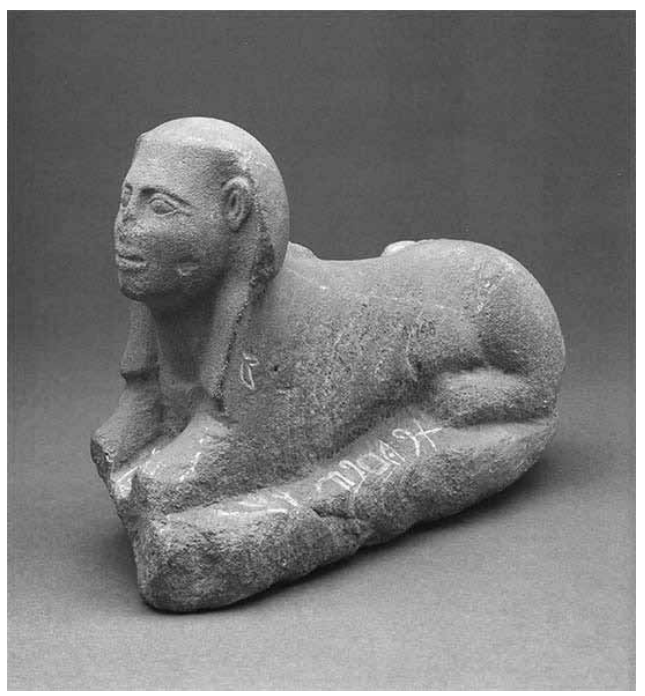

Figura 1 - Inscrição protossinaítica na base da esfinge, originária de Serabit el-Khadem. (PARKINSON, 1999)

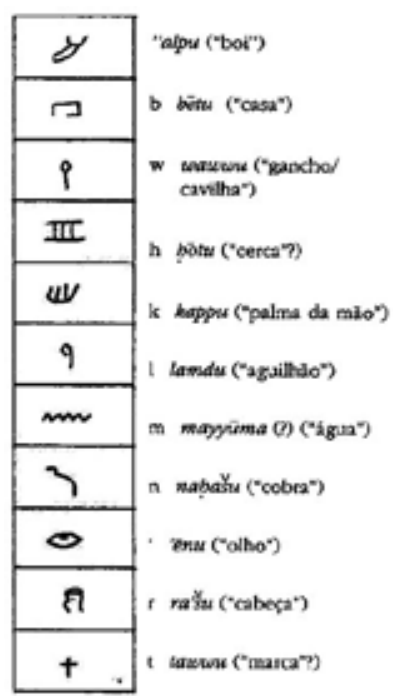

Figura 2 - Algumas formas protossinaíticas.

(HEALEY, 1996, p. 262) 
Ifrah (1989, p. 210) defende a teoria da invenção da escrita na mesma época, por volta de 1500 A.E.C., próximo da costa sírio-palestina, pelos fenícios, que abreviaram as escritas complicadas do Egito e da Mesopotâmia, então em uso no Oriente Próximo. Os fenícios, hábeis navegadores e grandes mercadores, conseguiram progressivamente propagar a sua invenção. A quase totalidade das escritas alfabéticas atualmente em uso descende, direta ou indiretamente, da antiga escrita alfabética fenícia.

Diringer (1964, p. 35-36 e 42) acredita que o alfabeto teve a sua origem entre 1800 e 1700 A.E.C., na região que compreende hoje Israel e a Síria, região submetida a muitas influências - a Mesopotâmia ao nordeste, o Egito a sudoeste, os hititas ao norte e os minoanos a oeste. Diringer levanta a possibilidade de que o alfabeto tenha sido uma invenção dos hebreus: os símbolos do alfabeto semítico do norte são artificiais e não representativos, como quase todos os escritos originais não alfabéticos, o que estaria de acordo com o segundo mandamento do Decálogo: "não farás para ti imagem de escultura, nem semelhança alguma [...]”. Não há prova de que os símbolos foram originalmente pictográficos, que a letra alef era a "cabeça de um boi vista de lado", o bet, uma "casa", o guimel, um "camelo", e assim por diante. Os nomes podem ter sido aplicados aos sinais, ao invés de terem sido derivados da representação dos objetos. Parece que a adoção dos nomes foi um meio mnemotécnico artificial, semelhante aos usados nas atuais cartilhas infantis, nos quais um A representa um "avião", o B, uma "borboleta", o C, um "cachorro". Há um exemplo semelhante no Talmude (Shabat 104a) para a memorização das letras, sem a utilização de imagens ou esculturas: as crianças compareciam ao local de estudos para aprenderem o alfabeto de duas em duas letras, da seguinte forma: alef bet, as duas primeiras letras, significando "aprenda compreensão" (a primeira letra, alef, também significa "estudar, aprender", conforme Berezin (2003, p. 20) a segunda letra, bet, é a primeira letra da palavra biná, "compreensão" (BEREZIN, p. 48); guimel dalet, a terceira e a quarta letras, significando "ajudar aos pobres" (BEREZIN, p. 77 e 94), e assim por diante.

Segundo Tur-Sinai (1950a, 1950b), o alfabeto de 22 sinais foi criado em Israel, e faz parte da tradição religiosa de Israel, teoria que está em desacordo com as ideias de Albright (1950, p. 24), que a considera contrária aos fatos.

Para Tur-Sinai (1950a, p. 88-89), tribos que migraram para o norte são as 
criadoras da escrita, e o processo de criação foi lento. Um semialfabeto básico, primitivo, foi criado por uma tribo cananeia no sul, área controlada pelo Egito. Traços deste tipo de escrita são encontrados nas inscrições protossinaíticas e na semítica do sul. Uma tribo do sudeste, que migrou para o norte, e finalmente habitou a antiga cidade de Ugarit, trouxe consigo, por volta da metade do segundo milênio A.E.C., uma ramificação da escrita semítica do sul, a qual modificou para atender às suas necessidades, adicionando novos sinais. Próximo ao final do segundo milênio, esta escrita se fundiu com escritas de outras tribos, também de Canaã. Após algumas gerações, este alfabeto foi utilizado em inscrições gregas e aramaicas. Consequentemente, o alfabeto não pode ter sido criado pelos cananeus da Fenícia. Os habitantes de Biblos, no final do segundo milênio A.E.C., utilizavam um sistema gráfico bem diferente, o pictorial-silábico, não alfabético. $\mathrm{O}$ alfabeto cananeu-hebraico surgiu em Biblos repentinamente, já desenvolvido.

Os nomes das letras eram originariamente os nomes de objetos retratados pelos símbolos. Os sons com os quais os nomes de objetos começavam receberam as representações pictoriais. Os cananeus e os gregos preservaram os nomes de alguns destes conceitos, e mantiveram até mesmo a ordem acidental na qual estes nomes foram ordenados. A tentativa ingênua de identificar estes conceitos pictóricos inicialmente no alfabeto hebraico quadrado, e finalmente nos alfabetos cananeu e protossinaítico, leva à seguinte conclusão: a letra alef seria identificada com a cabeça de um touro, a letra bet com uma casa, a letra guimel com um camelo, e assim por diante. Mas as formas e nomes das letras em geral não se encaixam nestas identificações. Mais da metade das letras nunca foram pictografias, já que são ampliações ou combinações de outras letras que, por sua vez, são símbolos mais simples. Consequentemente os alfabetos mencionados não podem ser representações pictóricas de conceitos designados pelos seus nomes.

Além disso, a tradição judaica não possuía nomes fixos para as letras, e os judeus não utilizavam as palavras alef, bet como nomes das letras até receberem influências dos gregos. Os falantes da língua hebraica provavelmente chamavam as letras pelos sons, como, por exemplo, $b a$ ou $g a$, e assim por diante. Nem mesmo em aramaico as letras eram chamadas pelos nomes (TUR-SINAI, 1950b, p. 168-169). 
A escrita passou por vários estágios de desenvolvimento até chegar à forma atual. Antes mesmo do início deste processo, existiam diversos métodos de comunicação antigos que seriam, segundo Diringer (1964, p. 20-22), os "embriões da escrita".

- Métodos acústicos (gritos, ruídos, tambores, flautas), que resultaram no desenvolvimento da língua.

- Métodos visuais (gesto, mímica, leitura dos lábios ou emprego da luz, fogo e fumaça).

- Marcas de propriedade: avisos feitos ao público de que um certo objeto pertence a uma certa pessoa ou grupo (marcação de gado feita por tribos árabes, marcas de canoas feitas por esquimós, marcas de rena dos lapões, tatuagens, marcas nos escudos e flâmulas).

- Meios mnemônicos: monumentos sobre sepulturas ou colunas de pedras, como em Gênesis 31:47-48 ("E chamou-lhe Labão 'Iegar Saadutá', o montão da testemunha, e Jacob chamou-lhe 'Galed"); Josué 22:26-27 ("Construiremos um altar que será uma testemunha [...]”), Josué 24:26-27 (“Esta pedra será uma testemunha para nós [...]”). Entalhes em varas e nós em cordas (quipu ${ }^{7}$, no Peru, usado para registrar fatos administrativos e impostos, como também poemas e obras literárias).

- Objetos palpáveis: seixos de diferentes tamanhos, cores e formas (tribo Cara, do Equador) para registrar números e acontecimentos.

- Pictografia: palavra de origem grega que significa "escrevendo com figuras", onde pequenas figuras simbolizam objetos e conceitos. Foi utilizada principalmente no Egito e na Mesopotâmia, desde antes de 3000 A.E.C., segundo Healey (1996, p. 250).

- Mágica por simpatia: o homem pré-histórico desenhava imagens de animais nas paredes de suas cavernas e as trespassava com seu estilete para assegurar a caçada que iria realizar.

Os estágios de desenvolvimento da escrita seriam, segundo Diringer (1964):

1. Iconografia: desenhos de objetos naturais, desconexos, fragmentários e estáticos. 
2. Escrita sintética ou ideográfica: série de quadros contando histórias.

3. Escritas do mundo antigo - analíticas (por exemplo, na Mesopotâmia, na Egito, em Creta, entre os minoanos, no vale do Hindu, na Ilha de Páscoa, os hieróglifos hititas, as escritas chinesa, maia e asteca, entre outros). São parcialmente ideográficas (usando símbolos pictográficos) e parcialmente fonéticas. Representam um estágio intermediário entre a escrita ideográfica pura e o sistema fonético puro. Segundo Hooker (1996, p. 9), a escrita analítica não se desenvolveu a partir de pictografias. A Paleta de ardósia do rei Narmer (cerca de 3000 A.E.C., Museu do Cairo) é um monumento que ilustra uma forma tardia de pictografia juntamente com o uso incipiente da escrita analítica, ou seja, figuras com legendas em hieróglifos.

4. Escritas embrionárias: os símbolos podem ser lidos em qualquer língua, não tendo necessariamente uma conexão com a língua falada. Assim, é possível compreender os sinais pictóricos e ideográficos de qualquer povo sem conhecer a língua falada e sua pronúncia.

5. Escrita alfabética: último e mais desenvolvido estágio de desenvolvimento da escrita, facilmente adaptável a quase todas as línguas. Faz parte dos sistemas fonéticos, nos quais a escrita é a reprodução gráfica da língua. Os sistemas fonéticos podem ser silábicos (sinais individuais representam sílabas, como nas escritas assíria e cipriota) ou alfabéticos. A escrita alfabética consta de uma coleção de um pequeno número de símbolos, geralmente entre 20 e 30, conhecidos como letras, que representam sons elementares da fala humana. Um sistema fantástico em que cada som é representado por um sinal.

Para Chomsky (1958, p. 75-80), a escrita se desenvolveu em estágios diferentes:

1. Pictográfico ou ideográfico: representado pelos hieróglifos do Egito Antigo e pictogramas da Índia - desenhos de figuras. Objetos e ideias eram representados por figuras. Muitos dos símbolos são figuras realistas que denotam o nome do objeto que representam. Com o tempo, as figuras se tornaram convencionais, cada vez se 
tornando menos parecidas com aquilo que representavam. Havia a necessidade de consentimento comum para a escolha das figuras, para que o sistema fosse útil na comunicação, o que deve ter sido possível já que o número de escritores no passado não deve ter sido grande. Segundo Hooker (1996, p. 9), as pictografias não têm referência linguística, apenas retratam um acontecimento ou transmitem uma mensagem por meio de uma série de desenhos, mas podem ter levado à verdadeira escrita mediante um processo de seleção e organização.

2. Escrita de palavras ou estágio logográfico: os símbolos e figuras passaram a ser associar a formas linguísticas ou palavras específicas. A figura do sol, por exemplo, poderia significar "brilho", "branco" ou "dia".

3. Estágio silábico: uma sucessão de figuras ou imagens foram empregadas para representar palavras ou sílabas, ou seja, a incorporação de elementos da língua falada na escrita. Segundo Hooker (1996, p. 9), na Suméria, no Egito e na China a escrita compreendia uma mistura de ideogramas (símbolos gráficos) ou pictogramas (imagens) com sinais silábicos (cada sinal representa uma sílaba). Segundo Healey (1996, p. 250), os sistemas de escrita do Antigo Oriente Próximo, a partir de 1700 A.E.C., incluíam um grande número de sinais silábicos.

4. Estágio uniconsonantal: acrofonia, usar uma figura para representar a sílaba inicial ou eventualmente o som inicial de uma palavra.

5. Estágio alfabético: estágio final de desenvolvimento.

Exemplos mais antigos de escritas alfabéticas, segundo Diringer (1964, p. 48):

- Inscrições cananeias antigas, datadas desde o $18^{\circ}$ ou $17^{\circ}$ séculos A.E.C.

- Alfabeto cuneiforme ugarítico (com sinais em formato de cunhas, do latim cuneus, feitos na argila úmida), registrado em milhares de tábuas de argila em alfabeto cuneiforme de 30 letras, encontradas na antiga cidade de Ugarit, a moderna Ras-Shamra, na costa da Síria, datadas em cerca de 1400-1200 A.E.C., segundo Healey (1996, p. 263-264). Muitas tábuas possuíam escrita cuneiforme silábica, bem 
conhecida pelos acadianos e hititas, enquanto outras possuíam uma escrita semítica ocidental. As tabuinhas continham registros de mitos, rituais e documentos administrativos, e uma delas continha uma lista de letras (Figura 3).

- Alfabetos semíticos do sul, usados na Arábia entre o segundo milênio A.E.C. e os tempos islâmicos, com ramificações na África.

- Alfabetos semíticos do norte, de meados do segundo milênio A.E.C., que possuem grande semelhança com o hebraico antigo, o fenício e o aramaico do primeiro milênio A.E.C. Exemplos: a Pedra Moabita ou Estela de Mesa (2Rs 3:4-5), datada de meados do nono século A.E.C.; a inscrição do sarcófago de Ahiram, encontrado em Biblos, atribuído ao $11^{\circ}$ século A.E.C. (Figura 4); o calendário Gezer, de cerca de 950 A.E.C., uma tábua de pedra macia descoberta em Gezer em 1908, na qual está gravada uma espécie de calendário agrícola, segundo Barnavi (1992, p. 17) (Figura 5).

Segundo Diringer (1964, p. 49), no final do segundo milênio A.E.C., o alfabeto se dividiu em quatro ramos: semítico do sul, cananeu, aramaico e grego.

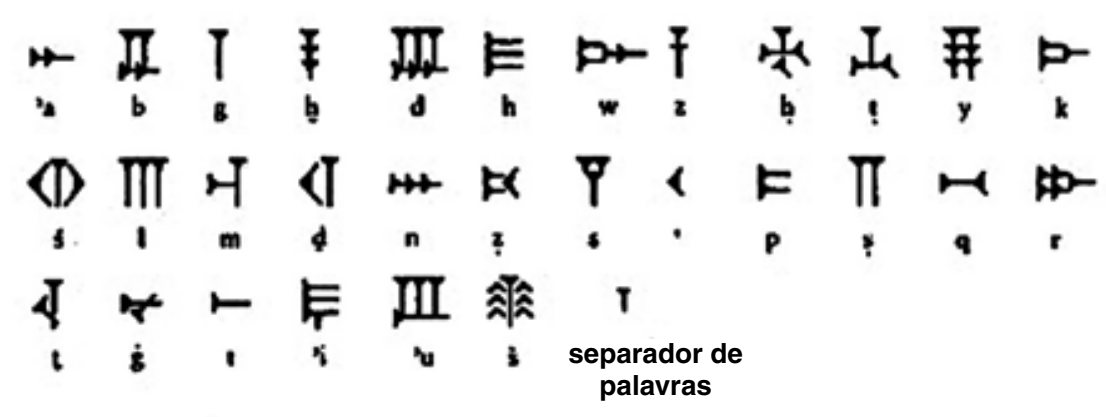

Figura 3 - Alfabeto cuneiforme ugarítico. (HEALEY, 1996, p. 266). 


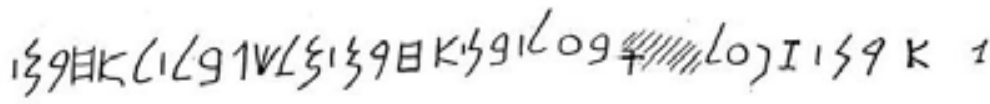

$$
\begin{aligned}
& 1 \xi \log 17+w W 179 k
\end{aligned}
$$

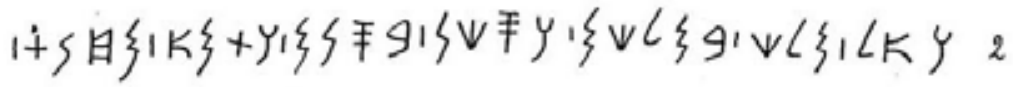

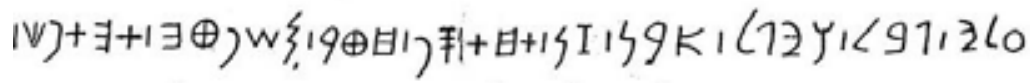

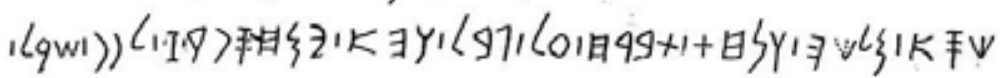

Figura 4 - Inscrição fenícia de Ahiram, Biblos, 11 século A.E.C. (HEALEY, 1996, p. 272)

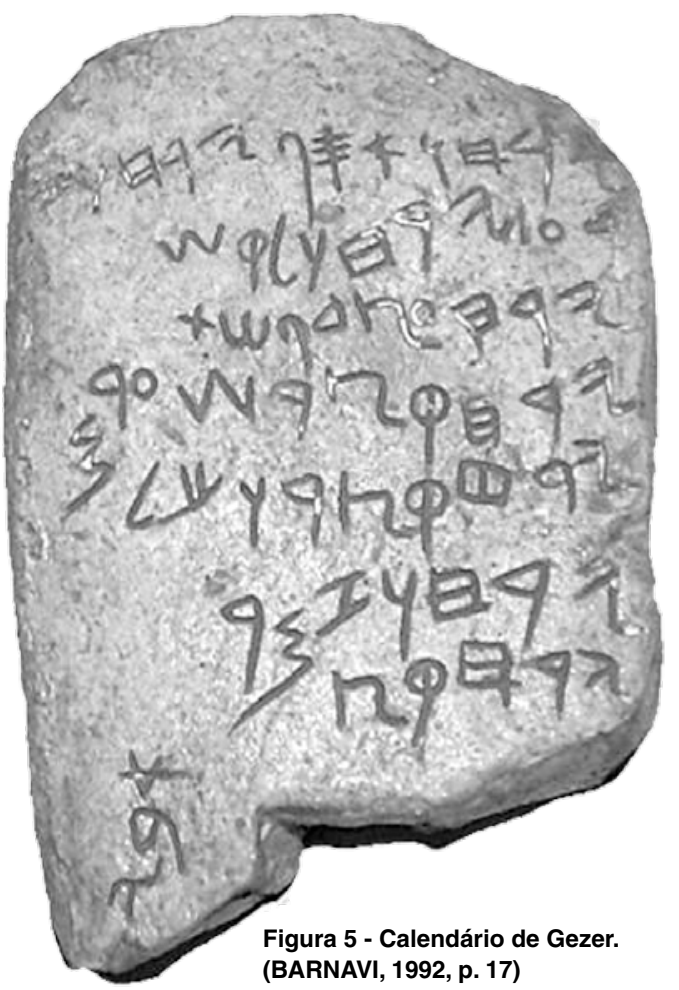


O alfabeto fenício de 22 letras, descendente direto do protossinaítico/cananeu e provável fonte do alfabeto grego, do aramaico e do hebraico, desenvolveuse por volta de 1050 A.E.C., segundo Healey (1996, p. 272). Um exemplo é a inscrição no sarcófago de Ahiram, de Biblos, datada de mais ou menos 1000 A.E.C. (Figura 4). A escrita fenícia se espalhou em todas as direções: para a Mesopotâmia, para Chipre, para o norte, na atual Turquia, para o sul, até os hebreus, para os arameus a leste, e pelas colônias púnicas dos fenícios em volta do Mediterrâneo.

A escrita fenícia foi provavelmente adotada pelos hebreus, sendo que a inscrição hebraica mais antiga é o calendário de Gezer (Figura 4). Não é fácil sentenciar se este texto é na verdade hebraico ou fenício. A escrita aramaica, por sua vez, tendo-se originado do fenício entre o décimo primeiro e o décimo séculos A.E.C., desenvolveu-se de forma rápida, tornando-se cada vez mais cursiva e simplificada, afastando-se do fenício. Tornou-se uma escrita internacional na época dos assírios, babilônios e persas, uma espécie de língua franca da diplomacia e do comércio, tendo-se dispersado por uma vasta região, desde o Egito até o norte da Índia. A partir do nono século A.E.C., a escrita fenícia, a hebraica e a aramaica começaram a divergir (HEALEY, 1996, p. 277-278) (Figura 6).

A escrita judaica é uma forma de aramaico ocidental que existiu a partir do terceiro século A.E.C., simultaneamente com o hebraico, que gradativamente foi caindo em desuso. A história desta escrita possui três fases: judaica antiga (250-150 A.E.C.), asmoneia (150-30 A.E.C.) e herodiana (30 A.E.C.-70 D.E.C.). Esta escrita judaica se espalhou pela diáspora judaica e tornou-se a "escrita quadrada", ou "escrita assíria", a letra de imprensa judaica padronizada, conhecida como escrita hebraica. Durante a Idade Média, foi a forma padrão da escrita judaica, que possuía também uma letra cursiva, conhecida como Rashi (HEALEY, 1996, p. 289).

Todos os alfabetos do Oriente Próximo Antigo que surgiram após a criação do primeiro alfabeto são alfabetos consonantais, e as vogais passaram a ser representadas em datas muito posteriores (na era cristã). A maioria dos jornais modernos escritos em hebraico ou árabe ainda são impressos sem vogais (HEALEY, 1996, p. 252). 


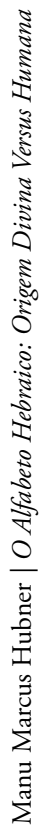

\begin{tabular}{|c|c|c|c|c|c|c|c|c|}
\hline & 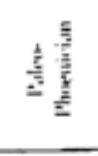 & $\frac{\frac{\pi}{2}}{\frac{2}{2}}$ & 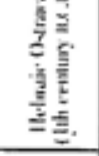 & $\frac{1}{\frac{1}{3}}$ & 资 & 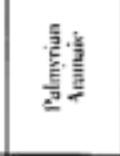 & 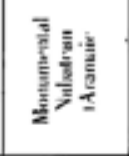 & 旁竞 \\
\hline . & $k$ & 4 & $F$ & 4 & $x$ & $x$ & 2 & $\kappa$ \\
\hline b & 4 & 4 & $g$ & 4 & 3 & $y$ & 3 & I \\
\hline $\mathrm{g}$ & 1 & 1 & 7 & 1 & 1 & $\lambda$ & $\rightarrow$ & 2 \\
\hline d & $\Delta{ }^{\circ}$ & $\triangle$ & $a$ & 4 & $y$ & $y$ & 7 & $ד$ \\
\hline $\mathbf{h}$ & 本 & 7 & a & $\exists$ & $n$ & $x$ & $\lambda$ & ה \\
\hline w & $Y$ & $Y$ & $y$ & 4 & , & $?$ & 1 & 1 \\
\hline$x$ & $I$ & $I$ & $x$ & I & 1 & 1 & 1 & T \\
\hline h & 日 & H & 9 & 目 & $n$ & $\mu$ & $\pi$ & $\mathbf{n}$ \\
\hline 1 & 8 & $\theta$ & 0 & $\oplus$ & 6 & 6 & 6 & 0 \\
\hline$y$ & $\chi$ & $z$ & 7 & $z$ & 4 & , & $s$ & , \\
\hline $\mathrm{k}$ & -y & $y$ & $\Rightarrow$ & $\gamma$ & 7 & $y$ & 3 & 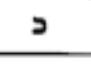 \\
\hline 1 & $c$ & $l$ & 1 & 6 & $\iota$ & $y$ & $b$ & b \\
\hline $\mathrm{m}$ & $y$ & $\eta$ & 5 & $y$ & $y$ & $s$ & 3 & $D$ \\
\hline $\mathrm{n}$ & 4 & $y$ & 3 & 9 & 1 & $s$ & $\mathrm{~J}$ & 2 \\
\hline $\mathrm{s}$ & 丰 & $\mp$ & 9 & 羊 & .3 & $y$ & $D$ & 0 \\
\hline . & 0 & 0 & 0 & $\circ$ & $u$ & $y$ & $y$ & $y$ \\
\hline$p$ & 2 & 1 & 7 & 7 & 2 & 3 & 3 & D \\
\hline$s$ & $r$ & 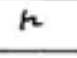 & $p$ & $r$ & $P$ & J & $S$ & $\mathbf{X}$ \\
\hline$१$ & $\varphi$ & $\Phi$ & $\psi$ & $\Phi$ & $P$ & $\mathfrak{s}$ & $\rho$ & $P$ \\
\hline $\mathbf{r}$ & 4 & 4 & 9 & 4 & 4 & 4 & 7 & 7 \\
\hline 3 & $w$ & $w$ & $w$ & $w$ & 6 & $v$ & 5 & $w$ \\
\hline$t$ & $x$ & $x$ & $x$ & $x$ & $n$ & 5 & $ת$ & $\mathrm{n}$ \\
\hline
\end{tabular}

Figura 6 - Comparação entre escritas. (HEALEY, 1996, p. 274) 
O termo "semítico" originou-se por associação a Sem, filho de Noé (HEALEY, p. 254). Em Gênesis 10:21-31 consta a lista de descendentes de Sem. Segundo Sáenz-Badillos (1993, p. 3), existem 70 línguas diferentes consideradas semíticas, sendo as principais ramificações:

- Semítico oriental:

- Acadiano: acadiano antigo; babilônico; assírio.

- Semítico ocidental:

- Eblaíta.

- Ugarítico.

- Cananeu: fenício e púnico; hebraico; moabita; edomita.

- Aramaico: aramaico antigo; aramaico do Império Persa; nabateu; hatreu; palmiriano; aramaico judaico; aramaico samaritano; siríaco; mandeu; dialetos aramaicos modernos.

- Semítico meridional:

- Sudárabe pré-islâmico: sabeu.

- Dialetos do norte pré-islâmico: tamudiano; libianita; safaítico.

- Árabe.

- Sudárabe moderno: mehri.

- Etíope: etíope clássico (gueez); amárico.

\section{Semítico Oriental}

Fazem parte deste grupo os alfabetos assírio-babilônio e acadiano. Exemplos: código de Hammurabi (aprox. 1800 A.E.C.), cartas de Amarna (1400 A.E.C.). O acadiano é a primeira língua semítica de que se tem registro. Língua usada na Mesopotâmia durante os grandes impérios dos babilônios e assírios. Sua escrita era cuneiforme e silábica, segundo Healey (1996, p. 255). O acadiano foi uma espécie de língua internacional de grande importância, segundo Chomsky (1958, p. 24-29).

\section{Semítico Ocidental}

- Aramaico: os documentos mais antigos são do oitavo século A.E.C. O aramaico floresceu, provavelmente, no décimo século A.E.C., como escrita dos arameus, semitas que habitavam a Síria e a Mesopotâmia e que foram conquistados pelos assírios (Damasco caiu em 732 A.E.C.). A língua e a escrita aramaica se expandiram após o sétimo século A.E.C., e tornaram-se, duzentos anos depois, as mais importantes e difundidas da Ásia Ocidental, tendo sido 
adotadas pelas grandes potências imperiais, como o Império Persa (cerca de 550-323 A.E.C.), segundo Diringer (1964, p. 58). Acabou por substituir outras línguas locais, como o fenício e o hebraico, que foi pouco usado na época posterior à Bíblia Hebraica. A próxima revolução linguística ocorreu com a disseminação do árabe na época das conquistas islâmicas do sétimo século E.C. (HEALEY, 1996, p. 255). O aramaico ainda é falado por alguns milhares de cristãos sírios e judeus do Curdistão e em várias outras localidades isoladas nas fronteiras do Irã, Iraque, Turquia e próximo a Damasco, na Síria.

O alfabeto aramaico possui as ramificações: oriental ou siríaco, da qual a linguagem do Talmude babilônico é uma variação, e ocidental ou palestiniano, da qual os textos Guemará de Jerusalém e os Targumim (traduções bíblicas) são exemplos. As porções aramaicas da Bíblia Hebraica também podem estar incluídas nesta categoria, segundo Chomsky (1958, p. 24-29) Inscrições em aramaico foram encontradas em diversos países: Egito, Israel, Síria, Arábia, Índia e países da Mesopotâmia e da Ásia Menor. São derivados do aramaico o hebraico, o nabateano-sinaítico-arábico, o palmiriano, o siríaco-nestoriano, o mandeano, o maniqueu, o arábico (originado do aramaico através dos alfabetos nabateano e neossinaítico), kharoshthi (Índia, Turquestão e Afeganistão), o parsi (Pérsia), o sogdiano (Ásia Central), o kök turki (tribos turcas da Sibéria, Mongólia e Turquestão, do qual deriva o alfabeto húngaro), o uiguir (Mongólia e Turquestão, a escrita do Império Mongol no $13^{\circ}$ século), o mongol (kalmuch, buriat, mandchu), o armênico e o georgiano, a escrita br hm (protótipo de cerca de 200 escritas utilizadas na Índia, no Tibet, Myanmar, Camboja, Tailândia, Indonésia e em partes das Ilhas Filipinas), e o coreano, derivado do ramo indiano, segundo Diringer (1964, p. 58). Os nabateus utilizavam a língua e escrita aramaica nos negócios públicos entre o quarto século A.E.C. e o primeiro da E.C., com inscrições em Petra, Madain Salih (Arábia Saudita) e sul da Síria; o palmiriano, escrita aramaica de Palmira/Tadmur, na Síria, foi utilizado entre o primeiro século A.E.C. até o século terceiro E.C.; o mandeu, no sul do Iraque, semelhante ao nabateu, nos primeiros três séculos E.C., segundo Healey (HEALEY, 1996, p. 289).

- Cananeu: fazem parte deste ramo o fenício e púnico, o hebraico, o moabita e o edomita.

- Moabita: conhecido devido à inscrição do rei Mesa, do nono século A.E.C. 
- Fenício: utilizado na Fenícia e em Cartago (alfabeto púnico), no norte da África, assim como nas colônias de Chipre, Sardenha e Sicília, segundo Diringer (1964, p. 58). As inscrições mais antigas são do $13^{\circ}$ ao $14^{\circ}$ séculos A.E.C. Os fenícios se identificavam como caneneus até o período romano. O fenício foi uma língua internacional na Síria e na Ásia Menor até ser substituída pelo aramaico no oitavo século, mas continuou sendo falada em Cartago até o quinto século, segundo Chomsky (1958, p. 24-29) (Figura 7).

Healey (1996, p. 281) acredita que os gregos adotaram o alfabeto fenício, e a comparação entre as letras é conclusiva. Como exemplo, a letra $A$, que conserva um elemento do pictograma - a cabeça de um touro (૪) invertida (A) - em grego se chama alfa $(\alpha)$, palavra sem nenhum significado em grego, mas que significa "touro" nas línguas semíticas ocidentais alpu em ugarítico e alef em hebraico). Esta regra se aplicaria a quase todos os nomes de letras gregas. $\mathrm{Na}$ obra do historiador grego Heródoto, do quinto século A.E.C., as letras se chamavam phoinikeia grammata, "letras fenícias", e supostamente foram trazidas à Grécia por Cadmo, príncipe fenício.

Diringer (1964, p. 54) também acredita na origem semítica da escrita grega, devido às formas e os nomes semíticos das letras, seus valores fonéticos e a direção da escrita do grego antigo - da direita para a esquerda. Seguiram alterações importantes, como a transformação de uma escrita consonantal em um alfabeto contendo vogais, mudança na direção da escrita após 500 A.E.C., que passou a ser da esquerda para a direita e de cima para baixo, e a criação das escritas uncial, cursiva e minúscula. Curiosamente, segundo Healey (1996, p. 263-264), alguns textos em grego antigo e em sudárabe eram escritos boustrophedon, como um boi arando o campo: da esquerda para a direita na primeira linha, da direita para a esquerda na segunda linha, da esquerda para a direita na terceira e assim por diante.

O alfabeto grego é o mais antigo sistema de escrita alfabética completamente desenvolvida, contendo tanto consoantes como vogais. $\mathrm{O}$ grego tornou-se o progenitor dos alfabetos europeus, como o etrusco, o latino e o alfabeto cirílico, de vários alfabetos da Ásia Menor (lício, frígio, panfiliense, lídio e cariano) e da África - o dos coptas (língua litúrgica que floresceu no Egito entre os séculos III e XIII), e até mesmo do alfabeto gótico, que sofreu outras influências, como dos caracteres romanos e rúnicos. O cirílico, escrita eslavônica baseada 
no alfabeto uncial grego do nono século, tornou-se a escrita oficial dos russos, ucranianos, búlgaros e sérvios (a teoria da invenção da escrita cirílica atribuída a São Cirilo baseia-se numa tradição tardia). O alfabeto latino se originou do etrusco (língua dos antepassados dos romanos), que, por sua vez, originou-se de um alfabeto grego primitivo. Os alfabetos modernos são adaptações do alfabeto latino para o germânico (inglês, alemão, sueco, dinamarquês), o românico (italiano, o francês, o espanhol e o romeno), o eslavônico (polonês, tcheco), as línguas ugro-finlandesas (finlandês, húngaro), o báltico (lituano, letão) e outras. A escrita rúnica das tribos góticas e germânicas também se originou de um alfabeto norte-etrusco (DIRINGER, 1964, p. 58) (Figura 7).

- Hebraico: partes mais antigas da Bíblia Hebraica provavelmente datam de 1300 A.E.C., e esta língua nunca deixou de ser falada ou escrita, apesar de ter sido restringida muitas vezes para estudo e liturgia. Segundo Chomsky (1958, p. 35), o cananeu foi adotado por Abraão e sua tribo, modificado e desenvolvido até se tornar o hebraico: "E os cananeus estavam morando na terra" (Gn 12:6). A língua de Canaã era muito avançada, e os filhos de Israel, ao conquistarem Canaã, aprenderam a língua dos conquistados, que mantiveram sua língua natal. Ainda existiriam exemplos de hebraico puro, sem influências do aramaico, como em Êxodo 15 (Canto de Moisés) e em Juízes 5 (Canto de Débora) (Figura 7).

- Ugarítico: O alfabeto ugarítico se parece com o acadiano, mas os sinais individuais são diferentes. O cuneiforme de Ugarit é o único exemplo de alfabeto cuneiforme suficientemente conhecido, e desapareceu quando Ugarit foi destruída pelos Povos do Mar, por volta de 1200 A.E.C. Era escrito da esquerda para a direita, como o grego e o latim, segundo Healey (1996, p. 263264). O alfabeto cuneiforme ugarítico está registrado nas tábuas de argila de Ugarit, a moderna Ras-Shamra, na costa da Síria, datadas em cerca de 14001200 A.E.C., e muitas possuem escrita cuneiforme silábica, enquanto outras possuem uma escrita semítica ocidental. As tabuinhas continham registros de mitos, rituais e documentos administrativos, e uma delas continha uma lista das letras. 


\section{Semítico Meridional}

- Árabe e seus vários dialetos: os mais antigos registros do árabe datam do terceiro século A.E.C. A língua se disseminou após o sétimo século, devido às conquistas islâmicas, e englobou grandes áreas da Ásia e da África, segundo Healey (1996, p. 255).

- Etíope e seus vários dialetos: usada na Abissínia, costa oriental da África. É empregada desde o quarto século, segundo Chomsky (1958). A escrita Sabeana espalhou-se pela África e deu origem à escrita etíope, e assim ao amárico, tigre e tigrinha, além de outras escritas da Abissínia (DIRINGER, 1964, p. 58).

\begin{tabular}{|c|c|c|c|c|}
\hline \multirow{2}{*}{$\begin{array}{l}\text { FENicio } \\
\text { ste. } X-D X \text { a.C. }\end{array}$} & \multicolumn{2}{|c|}{ MEREบ } & \multicolumn{2}{|c|}{ CRBCO } \\
\hline & $\begin{array}{l}\text { Inisio da } \\
\text { en crimta }\end{array}$ & Moderno & $\begin{array}{l}\text { Aprosimadare } \\
\text { se. V e.C. }\end{array}$ & Moderno \\
\hline Net & $n$ & $x$ & A & $A$ a Alfa \\
\hline Bk & 2 & 9 & F & B B Beta \\
\hline Geilned 1 & $A$ & 3 & $\Gamma$ & I $y$ Gama \\
\hline Dolet & \% & 7 & $\Delta$ & $\Delta$ \& Deka \\
\hline 346 & n & $\pi$ & F & F \& Epulea \\
\hline$w$ & 1 & 1 & $f$ & c Colpana \\
\hline Zevin & $\mathbf{I}$ & t & & 2 t \\
\hline Het & $\pi$ & $n$ & 日 & $\mathrm{H}$ ก $\mathrm{Eaz}$ \\
\hline Tha & $b$ & 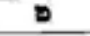 & $\oplus$ & Q 1 Teta \\
\hline Yod -2 & 4 & ? & $4=$ & 1. lota \\
\hline 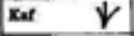 & 3 & 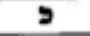 & $\mathbf{K}$ & K \& Cape \\
\hline Lamed & $\bar{b}$ & 5 & A & A $\lambda$ L Laebla \\
\hline Whn & $\theta$ & $D$ & $M(m)$ & $M \neq \mathbf{G}$ \\
\hline Noum & 3 & 2 & $N$ & $\mathrm{~N} v \mathrm{NI}$ \\
\hline Samoth & $v$ & 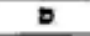 & 丰 $(x)$ & s $\&$ a \\
\hline agia & $y$ & $y$ & 0 & O \& Oetionos \\
\hline$n$ & 3 & $\boldsymbol{D}$ & $\Gamma$ & $\mathrm{II}=\mathrm{M}$ \\
\hline Slest & $r$ & $\mathbf{x}$ & $M(s)$ & m3 Sas \\
\hline Qot & $p$ & $P$ & 9 & 99 koppa \\
\hline noth & $y$ & 7. & $P$ & $P, 20$ \\
\hline satis & $\nabla$ & 2 & $\xi$ & I $\sigma$ sigma \\
\hline Tav & $n$ & $\pi$ & $T$ & $\mathrm{~T}, \mathrm{Tm}$ \\
\hline & & & $Y(u)$ & Y. lacklos \\
\hline & & & & $\bullet \mathrm{mi}$ \\
\hline & & & & $\mathrm{X} \times \mathrm{KM}$ \\
\hline & & & & $10 \mathrm{nd}$ \\
\hline & & & & A. Ones \\
\hline
\end{tabular}

Althbeto fenicio, habeu e groge.
Figura 7 - Comparação entre alfabetos: fenício, hebraico e grego.

(IFRAH, 1989, p. 211) 
A história da escrita está sendo escrita. Novos achados arqueológicos podem revolucionar esta história, como é o caso das 180 placas de barro gravadas com formas rudimentares de hieróglifos, encontradas em Abidos, no Egito, em 1998, pelo arqueólogo alemão Günter Dreyer, do Instituto Arqueológico Alemão, de cerca de 3200 A.E.C. (MITCHELL, 1999) ou as inscrições em forma de tridente do povo dravidiano, de cerca de 3300 A.E.C., encontrados em 1999 pelos arqueólogos americanos Jonathan Kenoyer e Richard Meadow (respectivamente das Universidades de Wisconsin e Harvard) nas escavações de Harappa, no Paquistão (PARPOLA, 2010).

\section{Referências}

ALBRIGHT, William Foxwell. The Origin of the Alphabet and the Ugaritic ABC Again. Bulletin of the American Schools of Oriental Research, n. 119, p. 23-24, out. 1950. Acesso em: 07 set. 2012. Disponível em: <http://www.jstor.org/stable/3218803>

BARNAVI, Élie. História universal dos judeus. Lisboa: Contexto, 1992.

BENNER, Jeff A. The ancient hebrew language and alphabet. College Station (TX): Virtualbookworm.com Publishing Inc., 2004.

BEREZIN, Jaffa Rivka. Dicionário Hebraico-Português. São Paulo: Editora Universitária de São Paulo, 2003.

BÍBLIA DE JERUSALÉM. 2a Impressão. São Paulo: Paulus, 2003.

BURGIERMAN, Denis R. O primeiro dia da história. Superinteressante. n. 7, p. 52-57, 1999.

CHOMSKY, William. Hebrew: the eternal language. Philadelphia: The Jewish Publication Society of America, 1958.

DIRINGER, David. A História do Álef Bet. Rio de Janeiro: Biblos, 1964. Vol. 1.

GINZBERG, Louis. The Legends of the Jews. Volume 1: Bible Times and Characters, From the Creation to Jacob. Oxford: Gutenberg Foundation, 2001.

GOLDWASSER, Orly. How the alphabet was born from hieroglyphs. Biblical Archaeology Review. v. 36, n. 2, mar./abr. 2010.

HEALEY, John F. O Primeiro Alfabeto. In: HOOKER, J. T. (org.) Lendo o passado: do cuneiforme ao alfabeto. A história da escrita antiga. São Paulo: EDUSP-Melhoramentos, 1996. p. 245-314.

HOOKER, J. T. (org.) Lendo o passado: do cuneiforme ao alfabeto. A história da escrita antiga. São Paulo: EDUSP-Melhoramentos, 1996.

IFRAH, Georges. Os números: história de uma grande invenção. Rio de Janeiro: Globo, 1989.

KAPLAN, Arieh. Sefer Yetsirá - O Livro da Criação: Teoria e Prática. São Paulo: Sefer, 2002.

MANGIN, Loïc. O enigma dos quipos. Scientific American Brasil - Etnomatemática, Ed. Esp., n. 35, p. 14-17, 2005.

MELAMED, Meir M. Torá: A Lei de Moisés. São Paulo: Sefer, 2001.

MITCHELL, Larkin. Earliest Egyptian Glyphs. Archaeology. v. 52, n. 2, mar./abr. 1999. Acesso em: 09 set. 2012. Disponível em: <http://www.archaeology.org/9903/newsbriefs/egypt.html> 
MORDELL, Phineas. The origin of letters and numerals according to the Sefer Yesirah. The Jewish Quarterly Review. University of Pennsylvania Press, New Series, v. 2, n. 4, Apr. 1912, p. 557-583. Acesso em: 08 ago. 2012. Disponível em: <http://www.jstor.org/stable/1450843> PARPOLA, Asko; PANDE, B. M.; KOSKIKALLIO, Petteri (eds.). Corpus of Indus Seals and Inscriptions. 3: New material, untraced objects and collections outside India and Pakistan. (Annales Academiae Scientiarum Fennicae, B 241, jun 2010) Helsinki: Suomalainen Tiedeakatemia. Acesso em: 09 set. 2012. Disponível em: <http://a.harappa.com/content/corpusindus-seals-and-inscriptions>

PARKINSON, Richard. Cracking Codes: The Rosetta Stone and Decipherment. Berkeley: University of California Press, 1999.

SÁENZ-BADILLOS, Angel. A History of the Hebrew Language. Cambridge: Cambridge University Press, 1993.

TUR-SINAI, Naphtali H. [Torczyner] The origin of the alphabet. The Jewish Quarterly Review. New Series, University of Pennsylvania Press, v. 41, n. 1, p. 83-109, jul. 1950a. Acesso em: 07 set. 2012. Disponível em: <http://www.jstor.org/stable/1452772>

. The origin of the alphabet (continuation). The Jewish Quarterly Review. New Series, University of Pennsylvania Press, v. 41, n. 2, p. 159-179, out. 1950b. Acesso em: 07 set. 2012. Disponível em: <http://www.jstor.org/stable/1452888> 